\title{
Adicionar um comentário: mecanismos de conversação em Weblogs e Fotologs brasileiros
}

\author{
Add a Comment: Conversation Mechanisms \\ in Brazilian Weblogs and Photoblogs
}

Raquel Recuero*

Universidade Católica de Pelotas

\begin{abstract}
RESUMO: O presente trabalho discute os mecanismos de conversação observados nos fotologs e nos weblogs brasileiros, a partir de um estudo realizado em $2006 \mathrm{e}$ 2007. Partindo de uma discussão do uso dos referidos sistemas como formas de conversação mediada por computador de forma assíncrona, são apontados elementos de estrutura da conversação, pares conversacionais e marcadores conversacionais que auxiliam no funcionamento dessas conversaçōes. Finalmente, discutem-se as semelhanças e diferenças dos dados e suas possíveis implicaçôes para estudos futuros das conversaçōes mediadas pelo computador.
\end{abstract}

PALAVRAS-CHAVES: Conversação mediada pelo computador; Weblogs; Fotologs; Conversação Assíncrona; Sociabilidade.

ABSTRACT: This paper discusses the conversation mechanisms observed in Brazilian weblogs and fotologs based on an ethnographic study carried out in 2006 and 2007. From a discussion of these systems usage as forms of asynchronous computer mediated conversation, we point out elements of conversational structure, conversational pairs and conversational markers that help the conversations. Finally, we discuss similarities and dissimilarities in the observed data and their possible implications for future computer mediated conversation studies.

KEYWORDS: Computer-mediated Conversation; Weblogs; Photoblogs; Asynchronous conversation; Sociability.

\section{Introdução}

Nos últimos anos, as ferramentas da chamada Comunicação Mediada pelo Computador na Lingüística Aplicada têm capturado a atenção de um grande número de pesquisadores (vide, por exemplo, MARCUSCHI;

* raquelrecuero@gmail.com 
XAVIER, 2004). Nesses trabalhos, a conversação tem sido focada principalmente em sua forma síncrona (NOBLIA, 1998; NEGRETTI, 1999; HERRING, 1999; COSTA, 2008, dentre outros), aqui compreendida como aquela que simula os eventos de uma conversação oral, mas que acontece de forma escrita na Rede (de um modo especial, os estudos focam os chats). No entanto, outras ferramentas têm sido apontadas pela literatura como relevantes, por apresentar elementos típicos da conversação, de um modo especial, os weblogs (De MOOR; EFIMOVA, 2004; HERRING et al., 2005) e os fotologs (McDONALD, 2007). Weblogs e fotologs são ferramentas originariamente direcionadas à publicação na Web e não à conversação. Por conta disso, é conseqüência de sua apropriação pelos atores sociais o seu uso conversacional. E nessa apropriação reside a criação de novas formas de intergir, tal como a conversação assíncrona, que é aquela que está espalhada por diversas identidades temporais e que não ocorre com a co-presença dos atores online (RECUERO, 2008c).

Para estudar as conversaçôes nos weblogs e fotologs, realizamos um estudo empírico durante os anos de 2007 e 2008, através de uma etnografia virtual, ${ }^{1}$ já bastante discutida e utilizada pela literatura como instrumento de pesquisa para os grupos sociais na Internet (HINE, 1998; AMARAL, 2008, entre outros) e da análise da conversação, igualmente utilizada para as conversações na Internet (NOBLIA, 1998; HERRING, 1999 etc.). A primeira técnica compreende a imersão no campo, onde os elementos que indicam a presença de conversações assíncronas de forma mais ampla são detectados por meio da observação. A segunda, verificaos elementos existentes na conversação de forma mais sistemática, auxiliando na percepção da estrutura dessas. A partir de alguns resultados do estudo empírico, discutiremos, então, diferenças e semelhanças entre as conversações observadas, bem como encaminhamentos para futuros estudos.

\section{A Conversação Mediada pelo Computador}

O estudo da conversação mediada pelo computador não é absolutamente novo, já tendo sido explorado por diversas vertentes teóricas, inclusive, pela

\footnotetext{
${ }^{1} \mathrm{O}$ conceito de "netnografia" (KOZINETS, 2002) também é muito usado como reapropriação do conceito de etnografia para o espaço virtual (vide MONTARDO; PASSERINO, 2006; AMARAL, 2008). No entanto, optamos por utilizar o conceito de etnografia virtual a partir de Hine (1998) por acreditar que se trata de uma proposta mais fiel à vinculação antropológica da etnografia.
} 
abordagem da Análise da Conversação (vide De MOOR; EFIMOVA, 2004; EFIMOVA; DE MOOR, 2005; HERRING et al., 2005, entre outros).

A Análise da Conversação (AC) tem suas origens nas décadas de 60 e 70 a partir de estudos nas areas da Etnometodologia e da Antropologia, quando os pesquisadores se preocupavam essencialmente com a estrutura das conversações (MARCUSCHI, 2006, p. 6). Atualmente, a perspectiva da AC é voltada para o estudo da estrutura das interações verbais (Kerbrat-Orecchioni, 2006). Com efeito, o estudo da conversação não passa apenas pela compreensão da linguagem, mas também pelos aspectos contextuais das estruturas de trocas conversacionais. Marcuschi (2006) define a conversação como "uma interação verbal centrada, que se desenvolve durante o tempo em que dois ou mais interlocutors voltam sua atenção visual e cognitiva para uma tarefa comum" (p.15). Trata-se, assim, de interaçóes negociadas e trocadas entre os atores sociais envolvidos em um processo de comunicação.

Embora a conversação seja mais imediatamente perceptível como prática falada, ou ainda, oral, ela também pode acontecer por intermédio da mediação. ${ }^{2}$ A mediação pela Internet já foi discutida como capaz de gerar conversações do tipo síncrono (vide HERRING, 1999; NOBLIA, 1998; MARCUSCHI, 2004; ARAÚJO, 2004), especialmente devido às características oralizadas das apropriaçôes realizadas pelos interagentes nas ferramentas de comunicação mediada pelo computador. No entanto, a conversação síncrona não é a única forma de conversação que pode ser mediada pelo computador.

Para Noblia (1998, online), "a CMC é a comunicação estabelecida entre as pessoas por meio de um computador". ${ }^{3} \mathrm{O}$ computador, assim, proporciona ferramentas por intermédio das quais a comunicação pode se estabelecer. Essas ferramentas proporcionam espaços onde a linguagem escrita é oralizada (MARCUSCHI, 2004; ARAÚJO, 2004), onde novos marcadores conversacionais e marcas verbais são desenvolvidos (OLIVEIRA, 2006), e onde construçōes lingüísticas específicas emergem e novos padrões de cooperação são estabelecidos.

Nesse sentido, defendemos, como outros autores (HERRING, 1999; PRIMO; SMANIOTTO, 2006), que a conversação mediada pelo computador pode também acontecer de forma assíncrona. Isso porque a conversação é caracterizada, como explica Marcuschi (2006), por uma estrutura de interação

\footnotetext{
${ }^{2}$ Marcuschi (2006), por exemplo, fala no estudo das conversações mediadas pelo telefone.

${ }^{3}$ Tradução da autora. No original: "The CMC is the communication established between people through a computer."
} 
realizada entre dois ou mais atores. Defenderemos, aqui que essa estrutura pode ser encontrada em ferramentas como weblogs e fotologs. Inicialmente, porém, precisamos discutir o que são essas ferramentas.

Weblogs são sites cuja estrutura é construída em torno de microconteúdo (pequenos blocos de texto) organizado de forma cronológica (BLOOD, 2002), freqüentemente com a presença de comentários e links para outros sites da mesma natureza, publicados com o auxílio de uma ferramenta facilitadora. ${ }^{4}$ Os weblogs tornaram-se extremamente populares na Internet, sendo apontados inicialmente como ferramentas de publicação semelhantes aos diários pessoais (CARVALHO, 2000; LEMOS, 2002; SIBILIA, 2006; MARCUSCHI, 2004 dentre outros). Posteriormente, outros usos foram igualmente discutidos pela literatura, ${ }^{5}$ dentre eles, as apropriações sociais ${ }^{6}$ (NARDI et al., 2004; MARLOW, 2004; MISHNE; GLANCE, 2006; SCHMIDT, 2007). Dentre esses estudos, destacam-se, para este trabalho, aqueles que consideram os blogs como espaços de conversação (HERRING et al., 2005; PRIMO; SMANIOTTO, 2006; EFIMOVA \& De MOOR, 2005; dentre outros). Para esses autores, os weblogs são espaços onde as interaçóes acontecem como conversações, especialmente por meio das práticas de comentários e links para outros blogs (MARLOW, 2004), que vão estruturar as trocas de mensagens nos sistemas.

Fotologs, por outro lado, são sistemas semelhantes, mas focados na publicação de fotografias. O Fotolog, ${ }^{7}$ que será o sistema objeto deste trabalho, é composto pelas imagens publicadas, que podem ser acompanhadas de um texto, de espaço para comentários e de uma lista de outros fotologs. As características de interação dos Fotologs foram pouco discutidas como objeto de pesquisa, ${ }^{8}$ especialmente no que diz respeito às interações textuais (quanto

\footnotetext{
${ }^{4}$ Elemento que dispensa, por exemplo, o conhecimento de HTML (Hypertext Markup Language), linguagem das publicações na Web.

${ }_{5}^{5}$ Para uma discussão mais ampla, vide Amaral, Recuero e Montardo (2008).

${ }^{6}$ Apropriações sociais aqui compreendidas como os usos da ferramenta enquanto formadora de grupos sociais, instrumento de cooperação, formadora de comunidades e etc.

${ }^{7}$ http://www.fotolog.com

${ }^{8} \mathrm{O}$ estudo de sites de publicação de fotografias é associado ou com o contexto das imagens publicadas (COHEN, 2005; SIBILIA, 2006), ou com o processo de produção e publicação das fotos (MILLER; EDWARDS, 2007), ou mesmo com a construção de história através das imagens (VRONAY, FARNHAN; DAVIS, 2001).
} 
a conversações visuais, vide McDONALD, 2007). No entanto, os comentários e as trocas interativas nos fotologs brasileiros já foram apontados como semelhantes aos dos weblogs, especialmente nas características conversacionais apontadas por Moor \& Efimova (2004).

\subsection{A Conversação Assíncrona e a Conversação Síncrona}

A conversação mediada pelo computador possui características específicas que a diferenciam de outras conversações mediadas. Primeiro, é um tipo de conversação que privilegia o anonimato, em detrimento da identificação. Assim, é comum que a própria linguagem e os contextos utilizados para a comunicação neste ambiente sejam apropriados pelos atores como elementos de construção de identidade (DONATH, 1999; HERRING, 1999; BOYD, 2007). A CMC também proporciona um distanciamento físico entre os interagentes, mas funcionando, muitas vezes, como um tipo de comunicação semelhante à face-a-face, embora a distância (REID, 1991). Outro elemento importante é a persistência. A CMC proporciona, pela mediação do computador, que as interaçóes persistam no tempo e possam ser acessadas em momentos temporais diferentes daquele em que foram emitidas (BOYD, 2007). Finalmente, a CMC é um tipo de comunicação que ainda privilegia especialmente o texto, mais do que o som e o video.

É justamente por causa dessa persistência que a conversação pode ser construída enquanto assíncrona. Mas como podemos compreender esse tipo de conversação?

Reid (1991) em seu trabalho sobre o IRC 9 aponta que a comunicação mediada pelo computador pode ser compreendida como síncrona ou assíncrona a partir de suas ferramentas. As ferramentas síncronas seriam aquelas que permitem uma expectativa de resposta imediata ou, em uma mesma identidade temporal, como as salas de chat. Seriam ferramentas que simulariam uma troca de informações de forma semelhante à interação face a face. Já nas ferramentas assíncronas, a expectativa de resposta não é imediata, mas alargada no tempo. Essas seriam ferramentas como o e-mail e os fóruns da Web. Murphy \& Collins (1999) e Ko (1996) também fazem consideração semelhante, mas ressaltam que tais características podem decorrer do uso e não

${ }^{9}$ Internet Relay Chat - Um tipo de protocolo de chat bastante popular na Internet na década de 90. 
da ferramenta em si. Ou seja, e-mails, por exemplo, apesar de ser um tipo de comunicação inicialmente assíncrona, podem ser utilizados de forma síncrona. Do mesmo modo, mensagens em um meio síncrono, como os mensageiros ${ }^{10}$ podem facilmente ser enviadas enquanto o usuário está deconectado, descaracterizando a sincronicidade da resposta. Assim, diríamos que a sincronicidade é mais uma característica da apropriação do meio e menos uma característica da tecnologia.

Deslocando, portanto, a discussão das ferramentas, diremos que uma conversação síncrona é aquela que é constituída entre os atores envolvidos em uma mesma identidade temporal, que estão, necessariamente, online ao mesmo tempo (co-presença). Já uma conversação assíncrona é aquela onde os atores envolvidos não dividem a mesma identidade temporal e que não há copresença, ou seja, não estão os interagentes conectados à Internet ao mesmo tempo. Essas conversações, assim, funcionam com mensagens que são emitidas em momentos de tempo diferentes, mas que ficam armazenadas em um espaço na Internet que permite sua recuperação e extensão (daí decorrentes da persistência defendida por BOYD, 2007).

A conversação assíncrona, por suas características, também pode acontecer em um (ou mais) espaço da Internet, bastando que os atores envolvidos referenciem essa conversação (por exemplo, nos comentários de vários weblogs de uma mesma rede - vide RECUERO, 2003), mas que estão, normalmente, centrados em um tópico ou assunto (vide McELHEARN, 1996; NOBLIA, 1998; De MOOR; EFIMOVA, 2004; HERRING et al, 2005 dentre outros). São comentários percebidos como parte da conversaçáo pelos atores, que freqüentemente referenciam a migração da conversa de um weblog para outro.

Uma vez discutidos os aspectos teóricos que norteiam essa pesquisa, apresentaremos, a seguir, os procedimentos metodológicos.

\section{Procedimentos Metodológicos}

Para construir as observações que são elencadas abaixo a respeito do campo, foi realizado inicialmente um estudo etnográfico virtual. A partir desta proposta, foram selecionados weblogss e fotologs brasileiros para análise, por meio de uma imersão do pesquisador no campo e da observação das trocas que

\footnotetext{
${ }^{10}$ Mensageiros são ferramentas semelhantes ao Google Talk e ao Live Messenger, onde é possível enviar mensagens a amigos conectados.
} 
seus sistemas abrigavam. A etnografia virtual é uma apropriação da etnografia enquanto método de pesquisa. Trata-se da imersão no campo de pesquisa, para a construção de impressões das apropriações e usos das tecnologias pelos atores sociais, por meio da participação ativa. Dentro dessa perspectiva, diversos autores (vide, por exemplo, HINE, 1998) têm utilizado a observação dos elementos de texto e da mediação pelo computador como bases para a etnografia virtual, procedimento que parte da ativa participação do pesquisador junto ao objeto de pesquisa (AMARAL, 2008) e é construído a partir das percepçôes deste.

Para esta pesquisa foram utilizados dados obtidos por meio da observação participante em weblogs e fotologs, a partir de dois estudos diferentes. O primeiro, ocorrido durante o ano de 2006 (janeiro a dezembro), registrou um estudo compreensivo sobre o uso de fotologs no Brasil, que foi tema da tese de doutoramento da autora. O segundo, realizado em 2007 (janeiro a dezembro), investigou a utilização dos weblogs por brasileiros. A observação foi realizada diariamente, por meio da navegação a partir de duas redes ego-centradas ${ }^{11}$ (uma para cada estudo), dos comentários e da participação. A rede foi construída com um grau de separação (ego e comentaristas de ego).

As observaçôes construídas por ambos os trabalhos foram registradas em diários de campo, dos quais foram retirados os exemplos que se seguem. ${ }^{12}$ Nos diários de campo, foram registradas as conversações observadas. Para este trabalho foram selecionadas, de forma arbitrária, 80 conversações (um total de 40 conversações para weblogs e 40 conversações para fotologs). As conversações foram escolhidas de forma cronológica (as 40 primeiras de cada ano de observação) e estendem-se por vários dias e, por vezes, meses.

A tabela abaixo faz um breve resumo dos dados das conversaçôes que serão analisadas:

\footnotetext{
${ }^{11}$ Uma rede ego-centrada é aquela onde a partir de um nó escolhido como ego estudamse os nós conectados a ele.

${ }^{12}$ Os exemplos observados nos fotologs e weblogs foram aqui reportados de forma anônima de acordo com as recomendaçóes para a ética em pesquisa no ciberespaço da Association of Internet Researchers (AOIR): http://www.aoir.org.
} 
TABELA 1

Dados das Conversações

\begin{tabular}{|c|c|c|}
\hline & Weblogs & Fotologs \\
\hline Número total de conversações & 40 & 40 \\
\hline Número de weblogs/fotologs observados como participantes & 88 & 25 \\
\hline Número total de participantes ${ }^{13}$ & 150 & 90 \\
\hline Número de turnos por conversação (média) & 5 & 3 \\
\hline Número de participantes por conversação (média) & 5 & 2 \\
\hline Número máximo e mínimo de turnos por conversação & $13(\max ) / 2(\min )$ & $20(\max ) / 2(\min )$ \\
\hline Número total de postagens ${ }^{14}$ & 46 & 29 \\
\hline Número total de comentários ${ }^{15}$ & 380 & 123 \\
\hline Numero total de interações & 426 & 152 \\
\hline
\end{tabular}

Essas conversações foram analisadas a partir da Análise da Conversação, tomando como base os elementos e marcadores conversacionais de Marcuschi (2006) e de Herring (1999). A partir dessa análise, foram construídas as observações que serão debatidas no próximo capítulo. Ressaltamos que os dados apresentados são ilustrativos das observações de campo, pois se trata de um estudo qualitativo.

\section{A Conversação em Weblogs e Fotologs}

A estrutura da conversação nos weblogs é bastante complexa (pois acontece em vários espaços de forma simultânea), mas relativamente organizada por conta de ferramentas que foram pouco a pouco acrescidas nos mecanismos de publicação. Essa conversação acontece principalmente em dois espaços: os textos publicados (postagens) e os comentários. Apesar disso, há conversações que utilizam trackbacks, conversações que ocorrem de modo simultâneo com outras e a participação de um número grande de atores (380). Esses textos podem ser interrelacionados por marcadores conversacionais de contexto, que permitem aos leitores compreender como a conversação está sendo estabelecida e quem está respondendo a quem. O seqüenciamento das interações pode acontecer

${ }^{13}$ Foram considerados participantes todos os interagentes nas conversaçôes. Nem todos, no entanto, possuem blog ou fotolog, daí a diversidade entre o número de participantes e o número de weblogs/fotologs que foram parte do estudo.

${ }^{14}$ Foram consideradas aqui apenas as postagens que fizeram parte das conversaçôes.

${ }^{15}$ Foram considerados aqui apenas os comentários que fizeram parte das conversaçôes. 
tanto de forma horizontal (entre vários weblogs) quanto de forma vertical (por exemplo, em vários comentários subseqüentes a uma mesma postagem).

Já nos fotologs, a conversação acontece de forma menos organizada, pois há uma quantidade menor de ferramentas que podem ser utilizadas como organizadores (apenas textos e comentários). Também há uma participação de atores mais limitada (apenas 123). Nos fotologs, como nos weblogs, a conversação acontece também em dois espaços, mas que são diretamente conectados: os textos que acompanham as fotos e os comentários acrescidos sob cada imagem. Os fotologs, aqui, possuem ainda a limitação de apenas permitir um número limitado de comentários (20 para fotologs do tipo comum e 100 para os do tipo gold camera). Talvez por conta disso, as conversaçōes quase sempre possuem seqüências horizontais. Seqüências verticais também aparecem, mas foram mais raramente observadas. Por fim, outra diferença observada entre as conversações que tomam forma nos weblogs e fotologs foi a presença de conversaçóes mais longas nos primeiros, e mais curtas nos segundos.

Essas organizações diferenciadas fazem com que os pares conversacionais sejam mais facilmente percebidos nos weblogs do que nos fotologs, embora estejam presentes em ambos os sistemas.

\subsubsection{Turnos, Seqüências e Pares Conversacionais}

Neste trabalho, um turno será compreendido como o momento de fala de cada ator na sequencia da conversação. Para Marcuschi (2006) o turno é parte da organização da conversação. A organização dos turnos nos weblogs e nos fotologs dá-se de uma forma complexa, pois as interaçōes podem acontecer nos textos publicados (postagens) e no espaço de comentários e tanto de forma de seqüência horizontal quando vertical. Os participantes da conversação, assim, precisam primeiramente perceber como se dá a organização dos turnos, por meio da observação dos pares conversacionais e das seqüências, para só depois se manifestarem. Essa percepção dá-se pela observação do que é falado, onde e como e para quem, para só depois acontecer a interferência do novo participante. Assim, os pares conversacionais, nesses sistemas, funcionam como organizadores, não apenas das seqüências de fala, mas igualmente dos turnos de fala.

Schegloff e Sacks (1973) explicam que esses pares conversacionais possuem posiçóes adjacentes e uma seqüência pré-determinada. Como a conversação nesses sistemas é assíncrona, os turnos se confundem com o próprio seqüenciamento da conversação. Marcuschi (2006) explica que os pares conversacionais são marcadores que vão além da organização dos turnos, 
estendendo-se ao nível se seqüência e auxiliando na organização dessas seqüências. Uma seqüência constitui um conjunto de turnos organizados. Nos sistemas de conversação assíncrona observados, esses pares são parte da compreensão da seqüência e dos turnos de fala.

Quando a resposta a uma conversação é feita em um novo post (texto do blog ou do fotolog), a referência aos turnos que contextualiza a conversação, quando feita, o é no corpo do texto, sob a forma de links para os outros blogs que comentaram o assunto. Esses links não apenas indicam a quem se responde, mas igualmente em qual contexto e como. Nesses casos, os turnos são organizados horizontalmente, com vários participantes comentando os assuntos discutidos na mesma conversação. No ato de referenciar o outro por intermédio de links, são estabelecidos não apenas o contexto da conversação, mas igualmente, o turno de fala. Mais do que isso, essa referenciação constitui um par conversacional, pois permite que a conversação seja compreendida como um todo (MARCUSCHI, 2006).

Além disso, a organização temporal dos textos publicados nos weblogs e fotologs (com data e horário) também auxilia na compreensão da organização dos turnos, que são espalhados temporalmente. Esse espalhamento, no entanto, pode ser marcado pelos links que vão auxiliar na recuperação da conversação em seu contexto.

Os turnos também podem acontecer no processo de comentários. Nesse caso, podem acontecer no mesmo espaço destinado aos comentários (no caso, a conversação acontece no referido espaço de um determinado blog e os participantes são os comentaristas - e por vezes, o próprio blogueiro); ou em vários espaços de comentários (no caso, a conversação acontece em vários espaços pertencentes a vários weblogs(fotologs diferentes).

No primeiro caso, os turnos são organizados de forma seqüencial vertical, um após o outro, e um novo participante pode acompanhar a conversação simplesmente seguindo a ordem dos comentários. Esses turnos verticais, portanto, são organizados de forma cronológica em um mesmo espaço de conversação.

No segundo caso, o acompanhamento dos turnos é um pouco mais complexo, pois eles acontecem de forma sequencial horizontal e é preciso entrar nos diferentes blogs/fotologs e para observar como a conversação se desenrolou. As referências ao contexto acontecem também via links (tanto para os participantes quanto para as postagens que foram colocadas nos blogs). Esses turnos horizontais, portanto, acontecem entre vários weblogs/fotologs, podendo gerar, cada um, novos turnos verticais. 
Assim, temos três tipos de organização de turnos nos weblogs, determinadas pelos pares conversacionais: Texto no weblog 1 - texto no weblog $2\left(\mathrm{~T}_{1}-\mathrm{T}_{2}\right)$; texto no weblog 1 - comentários no weblog $1\left(\mathrm{~T}_{1}-\mathrm{C}_{1}\right)$; Comentários no weblog 1 - Comentários no weblog $1\left(\mathrm{C}_{1}-\mathrm{C}_{1}\right)$. Esses são os tipos de pares conversacionais mais encontrados, embora, em casos mais raros, também apareçam comentários em um weblog 2 que respondem a comentários em um weblog $1\left(\mathrm{C}_{2}-\mathrm{C}_{1}\right)$ ou comentários em um weblog 2 que respondem a um texto em um weblog $1\left(\mathrm{~T}_{1}-\mathrm{C}_{2}\right)$ (Tabela 2$)$.

\section{TABELA 2}

Organização da estrutura dos turnos nos weblogs

\begin{tabular}{|c|c|c|}
\hline Tipo & Seqüiência & Exemplo $^{16}$ \\
\hline $\mathrm{T}_{1}-\mathrm{T}_{2}$ & Horizontal & $\begin{array}{l}\text { T1: No post anterior, sobre o mesmo assunto, a Usuária B (link para } \\
\text { o blog de Usuária B) comentou que (...) } \\
\text { T2: Como a Usuária A (link para o blog da Usuária B) comentou, } \\
\text { isso (...) }\end{array}$ \\
\hline $\mathrm{T}_{1}-\mathrm{C}_{1}$ & Vertical & $\begin{array}{l}\text { T1: Alguém sabe me explicar qual argumento dos que defendem o } \\
\text { direito a beber e dirigir? vi umas pesquisas que mostram que quase } \\
\text { metade das pessoas são contra a "lei seca". } \\
\text { C1: Usuário A disse: (7th July } 2007 \text { às 9:12 pm) } \\
\text { eu vou começar dizendo que nem sequer aceito o nome "lei seca" - } \\
\text { porque NÃO é uma proibição de beber. não é, então não é lei seca. } \\
\text { E não é uma proibição de dirigir. é proibido beber + dirigir. aliás, } \\
\text { sempre foi proibido. agora só começou a valer (...) }\end{array}$ \\
\hline$C_{1}-C_{1}$ & Vertical & $\begin{array}{l}\text { C1: ah, Usuário A, não querendo ser pentelha, mas já sendo: o último } \\
\text { parágrafo da carta dá margem pra, no mínimo, o cara dizer isso. } \\
\text { quem escreve o que quer, pode ter uma resposta que não quer. óbvio } \\
\text { que concordo contigo, etc, mas o azeredo tem todo o direito de } \\
\text { responder, vivemos em uma democracia, ora pois. } \\
\text { beijo } \\
\text { Usuário B em } 07.07 .2007 \text { às } 23: 36 \\
\text { C2: USUÁRIO B: a questão é que o azeredo é um servidor público. } \\
\text { quem tem de se explicar é ele, que está recebendo o meu, o seu, o } \\
\text { nosso dinheirinho para criar leis que sejam as melhores para o país, } \\
\text { não para uma ou duas empresas. e eu não falei nenhuma mentira no } \\
\text { último parágrafo, são informações públicas. se ele me acusasse de } \\
\text { leviandade ou falta de educação, tudo bem, mas de má-fé é inaceitável. } \\
\text { Usuário A em } 08.07 .2007 \text { às } 12: 01\end{array}$ \\
\hline
\end{tabular}

(continua)

\footnotetext{
${ }^{16}$ Os exemplos apresentados aqui foram coletados nas conversaçôes observadas em campo.
} 
(continuação)

\begin{tabular}{lll}
\hline $\mathrm{C}_{1}-\mathrm{C}_{2}$ & Horizontal & CWA: Acabo de publicar uma entrevista com ele: (link para o \\
& & $\begin{array}{l}\text { weblogs de usuário B) } \\
\text { Usuário B em 24.06.2007 às 20:00 }\end{array}$ \\
& CWB: Bem legal, parabéns! Tem que discutir o projeto mesmo! \\
& Usuário A em 26.06.2007 às 12:15 \\
\hline $\mathrm{T}_{1}-\mathrm{C}_{2}$ & Vertical & TWA: A discussão a respeito do projeto está acontecendo nos \\
& $\begin{array}{l}\text { weblogs (...) } \\
\text { CWB: Já comentei no blog do Usuário A (link para o weblogs de } \\
\end{array}$ \\
& Usuário A) sobre isso. \\
& Usuário C em 06.07.07 \\
\hline
\end{tabular}

Nos fotologs os turnos de fala são quase sempre organizados nos comentários ou entre texto-comentário e menos entre texto-texto. Assim, temos como organização dos turnos as trocas: Texto no fotolog 1 - comentário no fotolog $1\left(\mathrm{~T}_{1}-\mathrm{C}_{1}\right)$; comentário fotolog 1 - comentário fotolog $2\left(\mathrm{C}_{1}-\mathrm{C}_{2}\right)$; comentário fotolog 1 - comentário fotolog $1\left(\mathrm{C}_{1}-\mathrm{C}_{1}\right)$ (formas mais comumente observadas) e texto no fotolog 1 - texto no fotolog $2\left(\mathrm{~T}_{1}-\mathrm{T}_{2}\right)$. A estrutura comentário fotolog 1 - texto fotolog $2\left(\mathrm{C}_{1}-\mathrm{T}_{2}\right)$ não foi observada (Tabela 3).

\section{TABELA 3}

Organização da estrutura dos turnos nos fotologs

\begin{tabular}{lll}
\hline Tipo & Seqüência & \multicolumn{1}{c}{ Exemplo $^{17}$} \\
\hline $\mathrm{C}_{1}-\mathrm{C}_{2}$ & Horizontal & CFA: Usuário B said on 7/4/06 7:51 PM ... \\
& & $\begin{array}{l}\text { Nossa, que cabelo LINDO! Adorei =] } \\
{ }^{*}\end{array}$ \\
& & CFB: Usuário A said on 7/4/06 8:45 PM . . \\
& & $\begin{array}{l}\text { Haha, obrigada! Mas ainda tá escovado, recém saído do cabeleireiro, } \\
\text { quero ver como vai ficar depois de lavar e secar normalmente. O cara } \\
\text { garante que vai ficar bom, to torcendo :) }\end{array}$ \\
& & $\begin{array}{l}\text { E parabéns pra tua irmã! } \\
\text { Beijo! }\end{array}$ \\
\hline $\mathrm{C}_{1}-\mathrm{C}_{1}$ & Vertical & CFA: Usuário C said on 7/6/06 5:12 PM Ta a carinha daquela foto \\
& & de quando tu era um bebe. \\
& & CFA: Usuário A said on 7/7/06 7:44 AM Eu não envelheço, oi. \\
& & Mamãe passou formol em mim. \\
\hline
\end{tabular}

(continua)

${ }^{17}$ Os exemplos desta tabela foram coletados a partir das conversaçōes observadas em campo. 
(continuação)

\begin{tabular}{|c|c|c|}
\hline$T_{1}-C_{1}$ & Vertical & $\begin{array}{l}\text { TFA: expert em drinks. quer um pedaço? } \\
\text { CFA: Usuário } \mathrm{D} \text { said on } 7 / 6 / 063: 21 \mathrm{PM} \ldots \\
\text { eu queria um gole... } \\
\text { mas um pedaço tambem serve }=\mathrm{D} \\
\wedge \wedge\end{array}$ \\
\hline $\mathrm{T}_{1}-\mathrm{T}_{2}$ & Horizontal & $\begin{array}{l}\text { TFA: Parabéns para a Usuaria BBBBB!!!!!! Muitas felicidades! } \\
\text { TFB: Valeu gentesss que me mandaram parabéns! Usuária A, te } \\
\text { adoro! }\end{array}$ \\
\hline $\mathrm{C}_{1}-\mathrm{T}_{2}$ & Vertical & Não observado \\
\hline
\end{tabular}

Duas diferenças ficaram bastante claras na observação da estrutura da conversação dos blogs e dos fotologs. A primeira delas é que as conversações tendem a ser mais complexas nos weblogs, pois os pares conversacionais horizontais e verticais acontecem com maior freqüência, de uma forma especial os pares $\mathrm{T}_{1}-\mathrm{T}_{2} \mathrm{~T}_{1}-\mathrm{C}_{1} \mathrm{e} \mathrm{C}_{1}-\mathrm{C}_{1}$. No caso da presença dos primeiros, há um forte indicativo de que se trata de uma conversação que está sendo estabelecida entre weblogs. Já nos dois casos posteriores, a conversação está sendo estabelecida em um único weblog, mas entre comentaristas e blogueiro naquele espaço. No primeiro caso, as conversações estão espalhadas pela blogosfera. No segundo, estão concentradas em um único espaço.

A tabela abaixo (Tabela 4) apresenta os números de pares observados no corpus da pesquisa referentes aos weblogs ( 40 conversaçōes), nas 436 interações observadas. Cada número representa, portanto, um conjunto de duas interações, que compõem um par conversacional. ${ }^{18}$

TABELA 4

Dados verificados no corpus dos weblogs

\begin{tabular}{clc}
\hline Tipo & Seqüência & Número observado \\
\hline $\mathrm{T}_{1}-\mathrm{T}_{2}$ & Horizontal & 30 \\
$\mathrm{~T}_{1}-\mathrm{C}_{1}$ & Vertical & 80 \\
$\mathrm{C}_{1}-\mathrm{C}_{1}$ & Vertical & 45 \\
$\mathrm{C}_{1}-\mathrm{C}_{2}$ & Horizontal & 4 \\
$\mathrm{~T}_{1}-\mathrm{C}_{2}$ & Vertical & 3 \\
\hline
\end{tabular}

${ }^{18} \mathrm{O}$ número total de pares é inferior ao número de interaçōes pois nem todas as interações observadas compunham pares. 
Já nos fotologs, os pares que foram mais observados são os do tipo $\mathrm{C}_{1}-\mathrm{C}_{2}$ e $\mathrm{T}_{1}-\mathrm{C}_{1}$. Uma das primeiras observaçōes, por exemplo, foi o hábito de responder aos comentários nos fotologs dos comentaristas. Outra observação freqüente foi a das interaçôes entre o texto publicado e os comentários subseqüentes. Apesar de os demais pares terem sido observados, os dois primeiros são mais comuns e mostram, novamente, conversações entre vários fotologs (no primeiro par) e conversações entre o fotologueiro e os comentaristas (segundo par). Além disso, as conversaçóes observadas tinham menos turnos que as dos weblogs (uma media de três turnos, enquanto nos primeiros, as conversações tinham uma média de cinco turnos).

A tabela abaixo (Tabela 5) resume a freqüência dos pares observados no corpus dos fotologs do trabalho nas 40 conversações e 181 interações observadas. ${ }^{19}$

TABELA 5

Dados verificados no corpus dos fotologs

\begin{tabular}{ccc}
\hline Tipo & Seqüência & Número observado \\
\hline $\mathrm{C}_{1}-\mathrm{C}_{2}$ & Horizontal & 35 \\
$\mathrm{C}_{1}-\mathrm{C}_{1}$ & Vertical & 29 \\
$\mathrm{~T}_{1}-\mathrm{C}_{1}$ & Vertical & 8 \\
$\mathrm{~T}_{1}-\mathrm{T}_{2}$ & Horizontal & 2 \\
$\mathrm{C}_{1}-\mathrm{T}_{2}$ & Vertical & 0 \\
\hline
\end{tabular}

\subsubsection{Marcadores Conversacionais}

Marcuschi (2006) defende que os marcadores conversacionais são específicos e possuem funções conversacionais e sintáticas e seriam de três tipos: verbais, não-verbais e supra-segmentais. Os primeiros seriam aqueles que "não contribuem com informações novas para o desenvolvimento do tópico, mas situam-no no contexto geral, particular ou pessoal da conversação" (p. 62). Os segundos "estabelecem, mantêm e regulam o contato" (p. 63). Finalmente, o terceiro grupo constituiria fatores de organização e sentido para a conversação, tais como as pausas e o tom de voz.

${ }^{19}$ Novamente, o número total de pares é inferior ao número de interações pois nem todas as interaçóes observadas compunham pares. 
Quando se fala em comunicação assíncrona mediada por computador, no entanto, não podemos aplicar diretamente os marcadores da conversação oral. Há outra classe de marcadores (como defende Herring, 1999), que auxiliam nessa conversação. Enumeramos, neste trabalho, aqueles que foram observados na pesquisa.

\subsubsection{Marcadores Conversacionais de Turnos}

Um dos elementos fundamentais para os weblogs e fotologs é marcar o contexto e a ordem dos turnos em que as mensagens estão inseridas. Tais marcadores servem para situar o desenvolvimento do assunto, mostrando aos interagentes como a conversação está sendo desenvolvida. Isso ocorre porque esse contexto não é imediatamente discernível ao leitor que deseja participar da conversação e que não pode sequer compreender o que está sendo dito e por quem, devido à extensão temporal em que ocorrem as trocas. Assim, os participantes das conversaçôes utilizam artifícios para delimitar quem fala, quando e em qual contexto (assunto). Os marcadores observados foram:

a) Links - Os contextos das conversações nos weblogs e fotologs são geralmente demarcados pelos links utilizados pelos interagentes para referenciar a conversação. Em todas as conversações observadas, eles apareceram. Esses links podem aparecer tanto nos textos (postagens) quando nos comentários. Assim, por exemplo, se o participante A está comentando algo que foi publicado pelo participante $\mathrm{B}$, ele fará um link em seu blog/fotolog para $\mathrm{B}$. Esse link funciona como uma referência a quem se está conversando, ou ainda, a quem se responde (Figura 1). Do mesmo modo, no espaço de comentários, há sempre um espaço para o comentarista identificar-se por intermédio de um link para seu blog/fotolog. Os links, assim, mais do que meras indicações do caminho da conversação, tornam-se também marcadores de quem fala e do próprio processo interlocutivo, ou seja, indicam, além do assunto, o interagente que fala. Finalmente, os links podem também indicar os espaços onde a conversação está ocorrendo, contextualizando as interações que estão indicadas. Constituem-se em marcadores conversacionais na medida em que delimitam quem fala e quando fala, bem como podem apontar uma referência contextual. 


\section{Os amigos blogueiros, moradores em Itajai (SC) Tiago Berlim e Ricardo Aoki fazem o apelo e mostram as imagens e como ajudar.}

FIGURA 1: Exemplo de links (coloridos) enquanto marcadores conversacionais

Links foram observados como marcadores em todas as conversações observadas, tanto nos weblogs, quanto nos fotologs. Embora nem todas as interações contivessem links (especialmente no fotolog), sempre havia uma referência a um link anterior.

b) Trackbacks - As trackbacks são ferramentas que aparecem apenas nos weblogs e que podem ou ser acrescentadas a eles, ou estar inseridas no próprio sistema utilizado. Elas auxiliam a contextualizar outros weblogs que também estão falando do mesmo assunto. Funcionam pelo envio automático de links aos weblogs citados em uma postagem e que vão aparecer naquele weblogs, no espaço de trackbacks. Essas ferramentas mostram, em um determinado turno, outras reverberaçóes daquela mensagem.

As trackbacks podem aparecer dentro da janela de comentários de um weblogs, como parte da conversação que ali se estabelece, ou em um espaço próprio, normalmente denominado "trackbacks" (Figura 2).

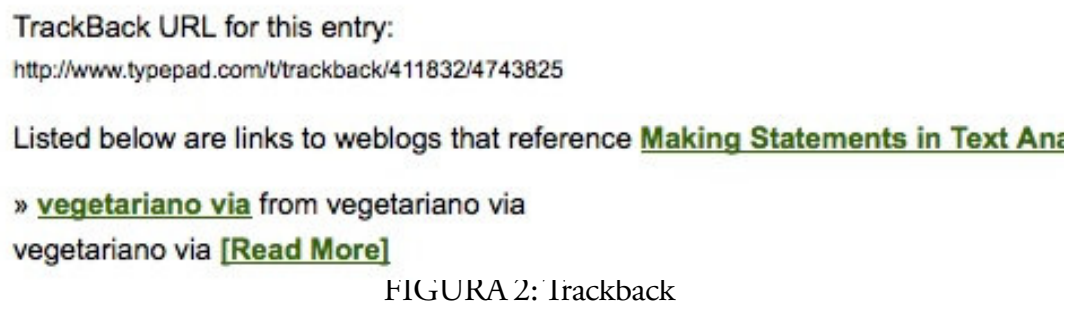

No entanto, apesar de apareceram nos weblogs participantes da pesquisa como espaço, apenas duas trackbacks foram efetivamente utilizadas nas conversações analisadas. Isso pode indicar que essa ferramenta é pouco utilizada enquanto marcador.

c) Data e Horário - Outro marcador que organiza a conversação nos weblogs e nos fotologs são as datas e os horários dos comentários e dos textos. Esses marcadores, colocados de forma automática (e, portanto, presentes em todas as conversaçóes analisadas), são essenciais para contextualizar 
temporalmente as interaçóes, permitindo que se acompanhe o momento em que cada coisa aconteceu de modo que o leitor possa reorganizar a conversação antes de decidir interferir nela (vide exemplo abaixo).

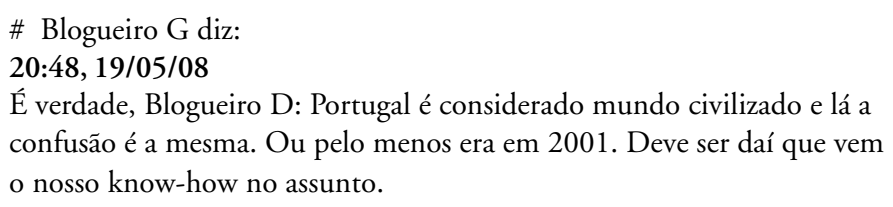

d) Assinaturas e Direcionamento - Além dos links, que auxiliam na identificação dos interagentes nos turnos conversacionais, a assinatura das postagens e dos comentários é igualmente importante para determinar quem fala. Assim, os pares são identificados pelos interagentes, que podem interferir na conversação estabelecida. As assinaturas vão, assim, estruturar a conversação como marcas de turnos. Estão presentes tanto nos weblogs quanto nos fotologs e em todas as conversações analisadas.

Outro elemento importante em conversações com mais de dois interagentes são os indicadores de direcionamento, que indicam aos demais para quem aquela mensagem é dirigida. Tais indicadores também aparecem em conversações assíncronas como modos de direcionar e escolher os turnos. São fundamentais para permitir que os pares conversacionais sejam identificados nas conversações em meio às diversas mensagens.

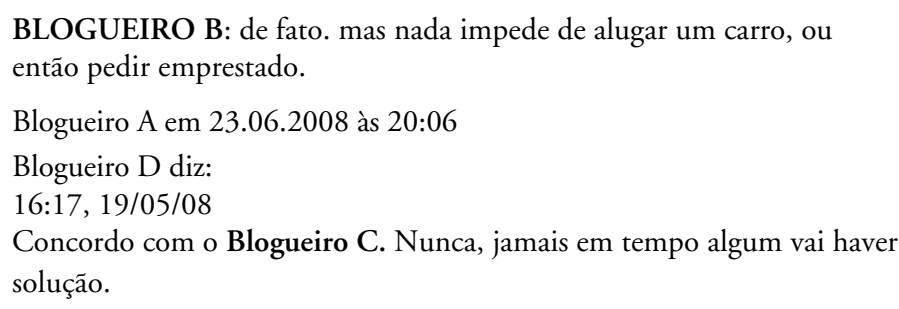

No exemplo acima, vemos dois indicadores de direcionamento em duas conversações síncronas em weblogs diferentes. Nos casos, os interagentes respondem a seu turno, indicando a quem estão direcionando a mensagem ou indicado o contexto ao qual pertence a mesma.

Os indicadores de direcionamento também podem ser utilizados para determinar vários turnos que estão sendo simultaneamente respondidos por vários interagentes da conversaçáo e apareceram também em todas as conversações observadas. 


\subsubsection{Marcadores Conversacionais de Informalidade}

Um dos elementos que aproxima a conversação nos weblogs e fotologs da conversação oral é a informalidade. Essa informalidade é caracteriza pelo uso de marcadores de linguagem oralizada, típicamente conversacional. Trata-se, portanto, da utilização da linguagem escrita para delimitar tanto marcadores verbais quanto não verbais ou paralingüísticos. Neste sentido, Boyd (2007) discute que as conversaçôes em sites de redes sociais como apropriaçóes dos atores da ferramenta para o propósito da socialização. Talvez por conta disso, a oralidade da linguagem seja um importante marcador de informalidade. Ela explica que os adolescentes, por exemplo, tendem a utilizar esses sites como extensões de seu espaço pessoal, para trocar informaçóes e, principalmente, para complexificar seus laços sociais. Esses marcadores são associados ao uso de onomatopéias, emoticons, abreviações, pontuação, gírias e à organização da linguagem.

As onomatopéias e os emoticons aparecem bastante nos weblogs e nos fotologs. Esses marcadores são bastante utilizados como forma de criar uma característica de informalidade para a linguagem utilizada nessas ferramentas (HERRING, 1999). Tais marcações emprestam características orais para a conversação que a aproxima da conversa face a face (Figura 3 ).

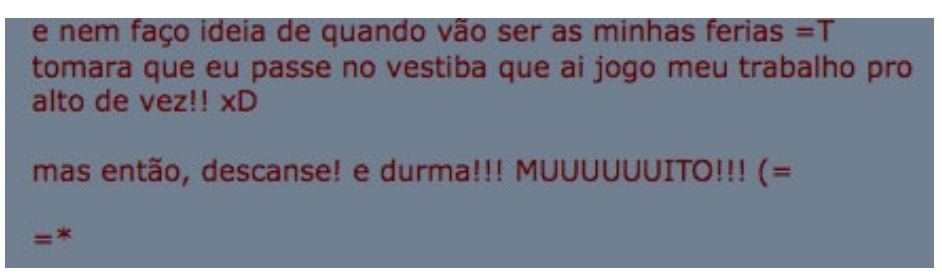

FIGURA 3 : Emoticons e oralização em um fotolog

Emoticons foram observados em todas as conversaçôes estudadas nos fotologs e weblogs, o que demonstra também sua importância para a interação.

Outros marcadores que também atuam nas conversações nos weblogs e fotologs são as abreviações e as pontuações. $\mathrm{O}$ uso desses elementos auxilia na informalidade na construção de sentido como conversação semelhante à oral, também emprestando informalidade às interaçôes. Novamente, tais marcadores apareceram em todas as conversações observadas nos weblogs e nos fotologs. 
pois é... como dic uma bela amiga minha, estou pronta para o caixao...

axo q peguei catapora... amanha eu vou saber,

FIGURA 4: Exemplos de informalidade em um fotolog

As construções informais foram observadas com maior predominância nos comentários dos weblogs, enquanto que os textos (postagens) parecem conter uma linguagem mais próxima da escrita-padrão. Observamos as construçōes informais em todas as conversações em weblogs e fotologs, embora não em todos os turnos.

Embora em alguns casos, a linguagem das postagens dos weblogs contenha muitos marcadores de informalidade (observamos apenas sete conversações que iniciavam com postagens informais), na maior parte deles (32 conversaçôes) a linguagem das postagens é mais formal. Já os comentários são ricos em marcações de informalidade (todos as tinham). Tal diferenciação, no entanto, não foi observada nos fotologs, onde tanto comentários como textos das postagens possuiam marcadores de informalidade semelhantes.

\subsubsection{Diferenças e Semelhanças nas Conversações em Weblogs e Fotologs}

Enquanto as conversações em weblogs costumam ser mais complexas, por conter um maior número de participantes, uma quantidade maior de pares conversacionais freqüentemente observados, a dos fotologs parece ser mais simples, conter menos turnos e menos pares. Enquanto a maior parte das conversações nos fotologs continha menos turnos (uma média de 3 turnos nas conversações observadas, como mostramos na Tabela 1), nos weblogs foi freqüente a observação de conversações mais longas (uma média 5 turnos).

Isso pode acontecer porque as conversaçôes, nos weblogs, podem, por características específicas da ferramenta, girar mais em torno de assuntos polêmicos, complexos e que são capazes de gerar uma grande quantidade de respostas e opinióes. Ao mesmo tempo, enquanto nos weblogs foram encontrados mais tipos de pares conversacionais (como elencamos na análise), tanto nos textos, quanto nos comentários; nos fotologs, os pares foram menos freqüentes e mais voltados para comentários. Outro elemento diferencial foi a presença dos marcadores de informalidade, mais voltados para a parte dos comentários nos weblogs, enquanto que estavam presentes em todos os espaços nos fotologs. 
Tais diferenças podem encontrar eco no modo de uso de cada tecnologia. Enquanto o weblog é uma ferramenta utilizada tanto para a socialização quanto para a difusão de informações e criação de valores sociais (vide Recuero, 2006 e 2008b), os fotologs parecem ser mais utilizados, ao menos no Brasil, para a criação e manutenção dos laços sociais (RECUERO, 2008a). Assim, possivelmente, a conversação nos blogs pode ter uma característica informacional muito forte, onde o debate e a discussão são valorizados pelos interagentes. Já nos fotologs, as conversações são talvez mais curtas por focarem mais elementos sociais, ou seja, focarem-se mais na criação e manutenção dos laços sociais. Nesse caso, as conversações nas diversas ferramentas assíncronas poderiam, por exemplo, ser determinadas pelos tipos de apropriações que a ferramenta sofre por cada grupo social. Além disso, outro elemento importante para a análise dessas conversações está relacionado às possibilidades técnicas de cada ferramenta, como já exposto por Herring (1999). Talvez a limitação do número de comentários nos fotologs, por exemplo, (o que não acontece nos weblogs) seja um dos fatores que gere a simplificação das conversações naquele espaço. Ou seja, as conversaçóes nos weblogs tenderiam a ser mais complexas porque há mais possibilidades de interação. Os weblogs também conteriam ferramentas de organização que poderiam auxiliar melhor na organização dessas conversaçôes. Como dissemos, as conversações assíncronas, por conta do espaço temporal dentro do qual ocorrem, necessitam de mais ferramentas de organização para possibilitar aos interagentes o acompanhamento e a participação. Neste caso, a possibilidade do dispositivo técnico seria um dos fatores fundamentais para as conversaçóes surgidas a partir dele (em uma abordagem semelhante à realizada por HERRING, 1999; MARCUSCHI, 2004; ARAÚJO, 2004 entre outros), mas não é o único fator determinante, uma vez que a apropriação da ferramenta pode, também, construir a conversação como um artefato cultural de um determinado grupo.

\section{Conclusões}

Este trabalho buscou discutir elementos observados nas conversações dos weblogs e dos fotologs. A partir de um estudo de campo de 80 conversaçóes (40 em cada sistema) e dos elementos discutidos pela literatura, apontamos mecanismos que possibilitam o funcionamento das conversaçóes assíncronas nesses espaços. Observamos turnos, seqüências e pares conversacionais, mostrando que nos weblogs há uma maior diversidade destes, que são mais verticais que nos fotologs (onde também há uma menor diversidade). 
Analisamos também a presença de marcadores conversacionais, que aparecem de forma bastante semelhante em ambos os sistemas. Finalmente, tendo apontado os elementos relativos aos turnos, às seqüências e aos pares conversacionais e discutidos os marcadores conversacionais como elementos de informalidade e sua presença nos referidos sistemas, pudemos apontar semelhanças e diferenças nas conversações assíncronas, discutimos então as possibilidades semelhanças e diferenças entre os weblogs e fotologs, bem como suas implicações para estudos da conversação.

Com base nesta discussão, levantamos a hipótese de que a apropriação dos elementos técnicos disponíveis nos sistemas pode estar diretamente relacionada com o surgimento das conversações assíncronas mantidas pelos seus usuários. Assim, parte do tipo de apropriação conversacional seria cultural e parte, derivada das possibilidades técnicas.

Neste artigo, procuramos demonstrar que os weblogs e os fotologs são espaços que podem ser apropriados como espaços conversacionais e descrever de que modo isso acontece e de que modo esses sistemas podem ser objetos de atenção dos pesquisadores em conversação. São apontamentos ainda iniciais e baseados em um estudo qualitativo, pontual e que não pretende esgotar o tema. No entanto, acreditamos que o trabalho apresenta elementos que poderão contribuir para a pesquisa nos mesmos sistemas no futuro e ser ampliados para outros tipos de conversação online.

\section{Referências}

AMARAL, A. Autonetnografia e inserção online. O papel do "pesquisadorinsider" nas subculturas da Internet. Anais do GT Comunicação e Sociabilidade do XVII Encontro Nacional da Compôs. São Paulo: PUCSP, 2008. p.1-15.

AMARAL, A.; RECUERO, R., MONTARDO, S. Blogs: Mapeando um objeto. Anais do VI Congresso Nacional de História da Mídia, 2008, Niterói. Anais do VI Congresso Nacional de história da Mídia. Niterói: UFF, 2008. p. 1-15.

ARAÚJO, J. C. A Conversa na Web: Um estudo da Transmutação em um Gênero Textual. In: MARCUSCHI, L.A.; XAVIER, A.C.S. Hipertexto e Gêneros Digitais: novas formas de construção do sentido. Rio de Janeiro: Lucerna, 2004, p.91-109.

BOYD, D. Social Network Sites: Public, Private, or What? In: Knowledge Tree 13. Austrália: 2007. Disponível em: <http://kt.flexiblelearning.net.au/tkt2007/ ?page_id=28>. Acesso em: 12 mai 2008. 
BLOOD, R. The weblog handbook: Practical advice on creating and maintaining your blog. Cambridge: Perseus Publishing, 2002. 144p.

CARVALHO, Rosa Meire. Diários íntimos na era digital: diários públicos, mundos privados. In: LEMOS, A.; PALÁCIOS, M (Org.). Janelas do ciberespaço. Comunicação e cibercultura. Porto Alegre: Sulina, 2000.

COSTA, A. L. S. Conversa Escrita Mediada pelo Computador: Uma perspectiva de Contínuo Tipológico de Produção. 2008. Dissertação (Mestrado) - Programa de Pós-Graduação em Letras, Universidade Federal do Paraná, 2008.

COHEN, K. What does the photoblog want? Media, Culture \& Society, n. 11, v. 27 p. 883-901, 2005. Disponível em: <http://mcs.sagepub.com/cgi/reprint/ 27/6/883>. Acesso em: 3 jan. 2007.

DE MOOR, A.; EFIMOVA, L. An Argumentation Analysis of Weblogs Conversations. In: Proceedings of the 9th International Working Conference on the Language-Action Perspective on Communication Modelling (LAP 2004), 2004. Disponível em: <https://doc.telin.nl/dsweb/Get/Document-41656/lap2004_ demoor_efimova.pdf $>$. Acesso em: 23 jun. 2008.

DONATH, J. S. Identity and deception in the virtual community. In M. A. SMITH, M. A.; KOLLOCK, P. (Ed.). Communities in Cyberspace. London: Routledge, 1999. p. 29-59.

EFIMOVA, L.; DE MOOR, A. Beyond personal webpublishing: An exploratory study of conversational blogging practices. In: Proceedings of the 38th Hawaii International Conference on System Sciences (HICSSO5), Los Alamitos: IEEE Press, 2005.

HERRING, S. C. Interactional coherence in CMC. Journal of Computer-Mediated Communication, 4 (4), 1999. Disponível em: <http://jcmc.indiana.edu/vol4/ issue 4/herring.html>. Acesso em: 23 jun. 2008.

Computer-mediated communication on the Internet. Annual Review of Information Science and Technology, 36, p. 109-168, 2002. Disponível em: <http://ella.slis.indiana.edu/ herring/arist.2002.pdf> Acesso em: 20 jun. 2008. HERRING, S. C.; KOUPER, I.; PAOLILLO, J. C.; SCHEIDT, L. A.; TYWORTH, M.; WELSCH, P.; WRIGHT, E.; YU, N. Conversations in the blogosphere: An analysis "from the bottom up". Proceedings of the Thirty-Eighth Hawai' International Conference on System Sciences (HICSS-38), 2005. Los Alamitos: IEEE Press: 2005. Disponível em: <http://ella.slis.indiana.edu/ -herring/blogconv.pdf>. Acesso em 23 jun 2008.

HINE, C. Virtual ethnography. Conference Proceedings of Internet Research and Information for Social Scientists, 25-27 March 1998, Bristol, UK: 1998. Disponível em: <http://www.sosig.ac.uk/iriss/papers/paper16.htm >. Acesso em 2 jul. 2008. 
KERBRAT-ORECCHIONI, C. Análise da Conversação. Princípios e Métodos. São Paulo: Parábola Editorial, 2006. 144p.

KO, Kwang-Kyo. Structural Characteristics of Computer-Mediated Language. A Comparative Analysis of InterChange Discourse. Electronic Journal of Communication, v. 6, n. 3, 1996. Disponível em: <http://www.cios.org/ EJCPUBLIC $\$ 964733218640 \$ \$ / 006 / 3 / 006315 . H T M L>$. Acesso em 20 jun. 2008.

KOMESU, F. C. Blogs e práticas de escrita sobre sin a Internet. In: MARCUSCHI, L.A.; XAVIER, A.C.S. Hipertexto e Gêneros Digitais: novas formas de construção do sentido. Rio de Janeiro: Lucerna, 2004. p.110-119.

KOZINETS, R. The field behind the screen: using netnography for marketing research in online communities. Journal of marketing Research, n.39, p.61-72, 2002.

LEMOS, André. A arte da vida. Diários pessoais e webcams na Internet. Cultura da Rede. Revista Comunicação e Linguagem, Lisboa, 2002.

MARCUSCHI, L. A. Análise da Conversação. São Paulo: Ática, 2006. 96 p. 2007. $170 \mathrm{p}$.

Cognição, Linguagem e Práticas Interacionais. Rio de Janeiro: Lucerna,

Gêneros Textuais Emergentes no Contexto da Tecnologia Digital. In: MARCUSCHI, L.A.; XAVIER, A.C.S. Hipertexto e Gêneros Digitais: novas formas de construção do sentido. Rio de Janeiro: Lucerna, 2004. p.13-67.

MARCUSCHI, L.A.; XAVIER, A.C.S. Hipertexto e Gêneros Digitais: novas formas de construção do sentido. Rio de Janeiro: Lucerna, 2004. 196 p.

MARLOW, C. Audience, structure and authority in the weblogs community. Anais of the International Communication Association Conference, May, 2004, New Orleans, LA, 2004.

MCDONALD, D. Visual Conversation Styles in Web Communities. Proceedings of the Hawaii International Conference on System Sciences (HICSS-40), Persistent Conversation Track. Kauai, HI: IEEE Computer Society. Jan. 4-7, 2007.

MCELHEARN, K. Writing Conversation: An Analysis of Speech Events in Email Mailing Lists. Language Studies Unit, Aston University, 1996. Disponível em: < http://www.mcelhearn.com/cmc.html>. Acesso em: 23 jun. 2008.

MILLER, A.; EDWARDS, W. Give and Take: A Study of Consumer Photo Sharing Culture and Practice. Anais da HCI - Human Computer Interaction, 2007.

MISHNE, G.; GLANCE, N. Leave a reply: An analysis of weblog comments. Paper presented at the workshop "Weblogging Ecosystem: Aggregation, Analysis and Dynamics," Edinburgh, UK. Disponível em: <http://www.blogpulse.com/ www2006-workshop/papers/wwe2006-blogcomments.pdf>. Acesso em: 3 jan. 2007. 
MONTARDO, S.; PASSERINO, L. Estudo dos Blogs a partir da Netnografia: Possibilidades e Limitaçôes. Revista RENOTE - Novas Tecnologias na Educação. V. 4 No 2, Dezembro, 2006. Disponível em: <http://www.cinted.ufrgs.br/ renote/dez2006/artigosrenote/25065.pdf>. Acesso em: 7 jul. 08.

MURPHY, K. L.; COLLINS, M. Communication Conventions in Institutional Electronic Chats. First Monday, 2(11), 1999. Disponível em: <http:// www.firstmonday.dk/issues/issue2_11/murphy/>. Acesso em 20 jun 2008.

NARDI, B. A.; SCHIANO, D. J.; GUMBRECHT, M.; SWARTZ. L. Why we blog. Communications of the ACM, 47 (12), p. 41-46, 2004.

NEGRETTI, R. Web-Based Activities and SLA: A Conversation Analysis Research Approach. Language Learning \& Technology, v. 3, n. 1, July 1999, p. 75-87. Disponível em: <http://llt.msu.edu/vol3num1/negretti/index.html>. Acesso em: 23 jun. 2007.

NOBLIA, M. V. The Computer-Mediated Communication, A New Way of Understanding The Language. Anais da International Conference: 25-27 March 1998, Bristol, UK IRISS '98: Conference Papers. Disponível em: <http:// www.intute.ac.uk/socialsciences/archive/iriss/papers/paper22.htm>. Acesso em: 20 jun. 2008.

OLIVEIRA, R. S. Marcas Verbais dos Aspectos Não-Verbais da Conversação nas Salas de Bate-papo na Internet. Seminário. Disponível em: <http://www.abed.org.br/ seminario2006/pdf/tc012.pdf>.Acesso em 20 jun 2008.

ÖRNBERG, T. Written Conversation: An Investigation of the Oral Features of Text Chat through Conversation Analysis. Thesis Seminar, 2003. Disponível em: <http://www2.humlab.umu.se/therese/conv_analysis.pdf>. Acesso em: 20 jun. 2008.

PRIMO, A.; SMANIOTTO, A. R. Blogs como espaços de conversação: interações conversacionais na comunidade de blogs insanus. E-Compos, v. 1, n. 5, 2006. Disponível em <http://www6.ufrgs.br/limc/PDFs/conversacao.pdf >. Acesso em: 20 jun. 2008.

RECUERO, R. Weblogs, Webrings e Comunidades Virtuais. 404nOtFound (UFBA), v. 1, n. 31, p. 1-15, 2003. Disponível em <http://www.facom.ufba.br/ ciberpesquisa/404nOtF0und/404_31.htm> Acesso em 20 jun 2008.

.a Tipologia de Fotologs Brasileiros no Fotolog.com. E-Compós (Brasília), v. 9, 2007. Disponível em < http://www.compos.org.br/files/05ecompos09 _RaquelRecuero.pdf $>$. Acesso em: 20 jun. 2008.

.b Estratégias de Personalização e Sites de Redes Sociais: Estudo de caso da apropriação do Fotolog.com. Comunicação, Midia e Consumo, São Paulo, v. 5, p. 35-56, 2008. 
.c DIGA-ME COM QUEM FALAS E DIR-TE-EI QUEM ÉS: A Conversação Mediada pelo Computador e as Redes Sociais na Internet. Anais do Congresso da Associação Brasileira de Pesquisadores em Cibercultura (ABCiber), São Paulo, 2008.

REID, E. Electropolis: Communication and Community On Internet Relay Chat. Honours Thesis. University of Melbourne, 1991. Disponível em: <http:/ /cyber.eserver.org/reid.txt>. Acesso em 23 jun 2008.

SACKS, H.; SCHEGLOFF, E.; JEFFERSON, G. A simplest systematics for the organization of turn-talking for conversation. Language, 50, p. 696-735, 1974. SIBILIA, P. O show da vida íntima na internet: blogs, fotologs, videologs e webcams. Anais da COMPÓS 2006 - XV Congresso da Associação Nacional de Programas de Pós-Graduação em Comunicação, 2006, Bauru-SP, Brazil. CDROM - XV COMPÓS, 2006.

SCHMIDT, J. Blogging practices: An analytical framework. Journal of Computer-Mediated Communication, Journal of Computer-Mediated Communication, n. 12, v. 4, article 13, 2007. Disponível em: <http:// jcmc.indiana.edu/vol12/issue4/schmidt.html>. Acesso em: 20 jun. 2007.

VRONAY, D.; FARNHAN, S.; DAVIS, J. PhotoStory: Preserving Emotion in Digital Photo Sharing. Internal research paper, 2001. Disponível em: <http:// research.microsoft.com/scg/papers/Photostory.pdf>. Acesso em 03 jan 2007.

Recebido em junho de 2008. Aprovado em dezembro de 2008. 